\title{
Isolation and identification of a high-efficiency phenol-degrading bacteria and optimization of its degradation conditions
}

\author{
Haili Sun ${ }^{1 *}$, Tianpeng Gao ${ }^{1,2 *}$, Guohua Chang ${ }^{1}$, Xisheng Tai ${ }^{1}$, Ruiqi Yang ${ }^{1}$, Qing Zhang ${ }^{1}$, Bin Yue ${ }^{1}$ \\ ${ }^{1}$ College of Geography and Environmental Engineering, Lanzhou City University, Lanzhou Gansu 730070, China \\ ${ }^{2}$ School of Biological and Environmental Engineering, Xi'an University, Xi'an 710065, China
}

\begin{abstract}
Phenol is widely used in China, it not only pollutes the environment, but also accumulates toxic substances in the human body through the food chain, further harming humans. In this experiment, a strain of high-efficiency low-temperature degradation phenol bacteria B5 was selected from the soil contaminated by organic matter of Lanzhou. Through research methods such as Gram staining observation, DNA extraction, PCR amplification, sequencing and comparison, it was found that this strain was Pantoea agglomerans. Through the subsequent optimization of degradation conditions, it was found that the B5 strain can degrade $500 \mathrm{mg} / \mathrm{L}$ of phenol to $24.8 \mathrm{mg} / \mathrm{L}$ in $36 \mathrm{~h}$. The ability to degrade phenol is stronger between $\mathrm{pH} 5.5-\mathrm{pH} 6.0$, and the ability to degrade phenol is higher in a medium containing $4-8 \mathrm{~g} / \mathrm{L}$ sodium chloride. This research can provide certain theoretical guidance for phenol degradation.
\end{abstract}

\section{Introduction}

Phenol is a simple phenolic organic weak acid, which is a common organic pollutant in industrial wastewater such as petroleum, fertilizer, paper making, rubber ${ }^{[1]}$. Phenol has strong toxic effects on many organisms. It has carcinogenic, teratogenic and mutagenic effects, so it has been included in the list of key pollutants in many countries ${ }^{[2]}$. Phenol can be directly toxic to the human body through contact with the skin and mucous membranes. It can chemically react with the proteins in the cell protoplasm to cause cell inactivation. Lowconcentration phenol solution can only denature protein, while high-concentration phenol solution can coagulate protein and eventually cause tissue necrosis ${ }^{[3]}$.

In addition to industrial wastewater, feces and nitrogen-containing organic matter will also produce phenolic compounds during the decomposition process. Therefore, a large amount of fecal sewage discharged from cities is also an important source of phenol pollution in water bodies ${ }^{[4]}$. After the water quality is polluted by phenol-containing wastewater, it will have many serious consequences, such as the destruction of the oxygen balance of the water body, etc. The arbitrary discharge of phenol-containing wastewater leads to deterioration of water quality, which seriously affects people's physical and mental health, and also restricts the sustainable development of cities. Therefore, it is urgent to seek effective environmental protection measures to treat phenol-containing wastewater.

Biological treatment of phenol-containing wastewater mainly uses the metabolism of microorganisms to convert harmful phenolic pollutants into non-toxic substances ${ }^{[5,6]}$, without secondary pollution, and has a large amount of treatment. Therefore, it has become the first choice for the harmless treatment of phenol-containing wastewater in China. The phenol-degrading bacteria that have been obtained include algae (Alga Ochromonas danica) [7], rhizobia (Rhizobia) [8], yeast (Yeast Trichosporon cutaneum) [9], and Pseudonomonas sp. ${ }^{[10]}$, etc. However, for the treatment of high-concentration phenol-containing wastewater, it is necessary to dilute the phenol concentration before entering the water to reduce the toxic effect on the organism, resulting in a substantial increase in the treatment cost. If the tolerance of microorganisms to phenol can be improved and the dilution factor can be reduced, it will be of great significance to the treatment of high-concentration phenol-containing wastewater. In this experiment, a microbial strain B5 that can efficiently degrade high-concentration phenol at low temperature was screened and isolated from the organic polluted soil of chemical plants, which has certain guiding significance for the treatment of high-concentration phenol-containing wastewater at low temperature in the future.

\section{Materials and methods}

\subsection{Main instruments}

Microscope, spectrophotometer, constant temperature incubator, shaker, PCR machine, etc.

\footnotetext{
* Corresponding author: Haili Sun and Tianpeng Gao, Emil: lzusun@163.com(H. S.), zkgtp@163.com(T. G.)
} 


\subsection{Source of strain isolation}

The source of the strain used in this experiment came from a chemical plant in Lanzhou, which was polluted by organic matter throughout the year. Soil microorganisms are mainly distributed on the surface of the soil and are sensitive to changes in the surface soil environment, so this experiment takes a $0-10 \mathrm{~cm}$ soil layer, removes the surface litter layer when sampling, and then uses the quarter method to sample. Put the collected soil sample into a sterile sealed bag and put it in the refrigerator at $20^{\circ} \mathrm{C}$ for later use.

\subsection{Medium formula}

(1) Select the medium: $\mathrm{K}_{2} \mathrm{HPO}_{4} 0.5725 \mathrm{~g} \cdot \mathrm{L}^{-1}, \mathrm{KH}_{2} \mathrm{PO}_{4}$ $2.9575 \mathrm{~g} \cdot \mathrm{L}^{-1}, \mathrm{MgSO}_{4} 0.25 \mathrm{~g} \cdot \mathrm{L}^{-1},\left(\mathrm{NH}_{4}\right)_{2} \mathrm{SO}_{4} 2.5 \mathrm{~g} \cdot \mathrm{L}^{-1}$, $\mathrm{CaCl}_{2} 0.0825 \mathrm{~g} \cdot \mathrm{L}^{-1}, \mathrm{NaCL} 0.25 \mathrm{~g} \cdot \mathrm{L}^{-1}, \mathrm{KCl} 0.25 \mathrm{~g} \cdot \mathrm{L}^{-1}$, Agar $10-20 \mathrm{~g} \cdot \mathrm{L}^{-1}, \mathrm{pH} 6.8$, sterilize at $121^{\circ} \mathrm{C}$ for 20 minutes, and then add phenol $100 \mathrm{ml} \cdot \mathrm{L}^{-1}$. (Note: All media should be protected from light during operation, because phenol is easily decomposed into pink or red benzoquinone when exposed to light.)

(2) Re-screening medium: $\mathrm{K}_{2} \mathrm{HPO}_{4} 0.5725 \mathrm{~g} \bullet \mathrm{L}^{-1}$, $\mathrm{KH}_{2} \mathrm{PO}_{4} 2.9575 \mathrm{~g} \cdot \mathrm{L}^{-1}, \mathrm{MgSO}_{4} 0.25 \mathrm{~g} \cdot \mathrm{L}^{-1},\left(\mathrm{NH}_{4}\right)_{2} \mathrm{SO}_{4}$ $2.5 \mathrm{~g} \cdot \mathrm{L}^{-1}, \mathrm{CaCl}_{2} 0.0825 \mathrm{~g} \cdot \mathrm{L}^{-1}, \mathrm{NaCl} 0.25 \mathrm{~g} \cdot \mathrm{L}^{-1}, \mathrm{KCl} 0.25$ $\mathrm{g} \cdot \mathrm{L}^{-1}$, Agar $10-20 \mathrm{~g} \cdot \mathrm{L}^{-1}, \mathrm{pH} 6.8$, sterilize at $121^{\circ} \mathrm{C}$ for 20 minutes, and then add phenol $500 \mathrm{ml} \cdot \mathrm{L}^{-1}$.

(3) Acclimatization medium: peptone $10 \mathrm{~g} \cdot \mathrm{L}^{-1}$, yeast extract $5 \mathrm{~g} \cdot \mathrm{L}^{-1}, \mathrm{NaCl} 5 \mathrm{~g} \cdot \mathrm{L}^{-1}, \mathrm{pH} 6.8$, sterilized at $121^{\circ} \mathrm{C}$ for 20 minutes, and then $500 \mathrm{ml} \cdot \mathrm{L}^{-1}$ phenol is added.

\section{Experimental methods}

\subsection{Screening and isolation of strains}

Take $10 \mathrm{~mL}$ of contaminated soil sample in a $50 \mathrm{ml}$ sterile centrifuge tube, add $30 \mathrm{ml}$ of sterile water and mix thoroughly. After standing for a few minutes, on a sterile workbench, use a pipette to draw $200 \mu \mathrm{L}$ of supernatant, spread it evenly on the selection medium with a spreading rod, and then place it at a constant temperature of $25^{\circ} \mathrm{C}$ and 200r/min Cultivate for $72 \mathrm{~h}$ in an incubator. Select a single colony according to the shape, size, color, gloss, softness, transparency, edge shape, swelling degree, and surface smoothness of the colony grown in the culture medium, and inoculate it with the plate streak method on the newly sterilized selection medium, culture for $72 \mathrm{~h}$ in a constant temperature incubator at $25^{\circ} \mathrm{C}$. Further purify the strain, repeat the above step, and separate and purify the single colony again 3 times by the plate streaking method. Through multiple screening and separation, two pure cultures of phenol-degrading bacteria with the best growth and the largest colony area were finally selected.

\subsection{Preservation of strains}

There are many methods for preservation of bacteria, including: liquid paraffin method, low temperature regular transplantation method, sand preservation method, liquid nitrogen ultra-low temperature preservation method. In this experiment, the liquid paraffin method was used to preserve the selected phenol-degrading bacteria.

Firstly, on a sterile workbench, inoculate the most efficient phenol-degrading strains screened out on the rescreening medium, and incubate them in a shaker at $25^{\circ} \mathrm{C}$ and $200 \mathrm{r} / \mathrm{min}$ for 36 hours. Microscopic observation shows that the concentration of bacterial turbidity is about $2 * 10^{8} \mathrm{CFU} / \mathrm{ml}$, it can be made into bacteria liquid. Then, draw $1.0 \mathrm{~mL}$ of bacterial solution and $0.5 \mathrm{~mL}$ of $30 \%$ glycerol in a $1.5 \mathrm{~mL}$ cryostat tube for strains. Save three copies of each strain, label them and store them in a refrigerator at $-80^{\circ} \mathrm{C}$ for subsequent experiments.

\subsection{Molecular identification of bacterial species}

(1) PCR amplification

In this experiment, two universal primers (27F, 1492R) were used for PCR amplification, and the reaction system used was $25 \mu \mathrm{L}$ each. The PCR reaction system is shown in Table 1:

Table1. PCR reaction system

\begin{tabular}{cc}
\hline Name & Dosage $(\mu \mathrm{L})$ \\
\hline Phanta Max Master Mix & 12.5 \\
Primer 1 (27F) & 1 \\
Primer 2 (1492R) & 1 \\
Bacteria & 1 \\
ddH $_{2} \mathrm{O}$ & 9.5 \\
\hline
\end{tabular}

(2) 16S rDNA sequencing comparative analysis

The PCR amplification product of the strain was sent to Xi'an Kinke Jersey Biotechnology Co., Ltd. for analysis and sequencing, and the $16 \mathrm{~S}$ rDNA sequence fragment of the strain was obtained. The measured sequences were compared and analyzed in NCBI's BLAST program, and the strains with the highest similarity were selected.

\subsection{Determination of phenol degradation ability}

(1) Correlation test between cell concentration and phenol degradation ability

The strain was cultured in the acclimation medium to the logarithmic growth phase $\left(\mathrm{OD}_{600}=0.5-1\right)$, and the bacteria were collected by centrifugation at 7000rpm for $5 \mathrm{~min}$. Resuspend the bacteria in a re-screened liquid medium containing $500 \mathrm{mg} / \mathrm{L}$ of phenol according to the wet reuse of the bacteria, and the final bacteria content reached $1 \mathrm{~g} / \mathrm{L}, 2 \mathrm{~g} / \mathrm{L}, 4 \mathrm{~g} / \mathrm{L}, 8 \mathrm{~g} / \mathrm{L}, 16 \mathrm{~g} / \mathrm{L}$. Then they were cultured in a constant temperature incubator at $25^{\circ} \mathrm{C}$ and $200 \mathrm{r} / \mathrm{min}$, and samples were taken every 12 hours to monitor the phenol content.

(2) Correlation test of phenol degradation ability of strains under different $\mathrm{pH}$ conditions

The strain was cultured in the acclimation medium to the logarithmic growth phase $\left(\mathrm{OD}_{600}=0.5-1\right)$, and the bacteria were collected by centrifugation at 7000rpm for $5 \mathrm{~min}$. Resuspend the bacteria in the re-screened liquid 
medium with different $\mathrm{pH}(\mathrm{pH} 4.5,5.0,5.5,6.0,6.5,7.0)$ to make the content of the bacteria in the medium $8 \mathrm{~g} / \mathrm{L}$. Then they were cultured in a constant temperature incubator at $25^{\circ} \mathrm{C}$ and $200 \mathrm{r} / \mathrm{min}$, and samples were taken every 12 hours to monitor the phenol content.

(3) Correlation test of strain phenol degradation ability under different salt concentration conditions

The strain was cultured in the acclimation medium to the logarithmic growth phase $\left(\mathrm{OD}_{600}=0.5-1\right)$, and the bacteria were collected by centrifugation at $7000 \mathrm{rpm}$ for $5 \mathrm{~min}$. Resuspend the bacteria with acclimation media containing different sodium chloride concentrations (sodium chloride concentrations are $0.5 \mathrm{~g} / \mathrm{L}, 1 \mathrm{~g} / \mathrm{L}, 2 \mathrm{~g} / \mathrm{L}$, $4 \mathrm{~g} / \mathrm{L}, 8 \mathrm{~g} / \mathrm{L}, 16 \mathrm{~g}, 32 \mathrm{~g} / \mathrm{L}$ ), The cell content in the culture medium was $8 \mathrm{~g} / \mathrm{L}$. Then they were cultured in a constant temperature incubator at $25^{\circ} \mathrm{C}$ and $200 \mathrm{r} / \mathrm{min}$, and samples were taken every 12 hours to monitor the phenol content.

\subsection{Determination of phenol content}

Through ultraviolet-visible spectrophotometric analysis and HPLC C-18 column, with methanol, formic acid, and double-distilled water in a ratio of 33:8:1 (volume ratio), preparatory experiments to determine the internal standard.

\section{Results and analysis}

\subsection{Strain isolation and morphological observation}

After separation and purification, 15 strains of phenoltolerant bacteria were obtained at $18^{\circ} \mathrm{C}$. After further screening, a strain that grows best at low temperature and has good degradation performance on phenol was finally determined, and it was named BF5.

\subsection{Strain identification}

(1) Detection and analysis of PCR products of 16S rDNA The amplified PCR products were measured by an agarose gel electrophoresis instrument and observed with an ultraviolet gel imager. The gel electrophoresis pattern of PCR products is shown in Figure 3.5. The electrophoresis bands are clear and there is no dragging phenomenon, indicating that these PCR amplified products can be used in subsequent experiments.

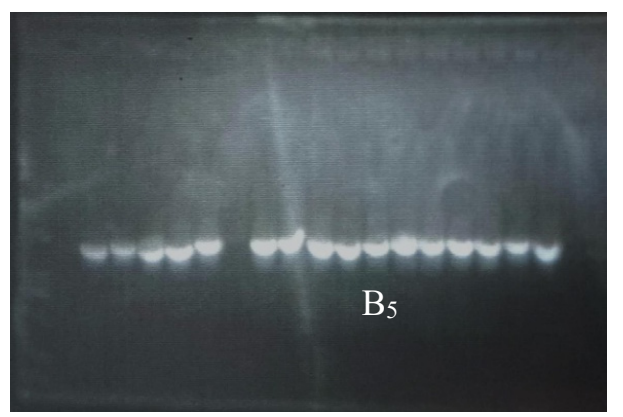

Figure 1. Gel electrophoresis map of PCR products
(2) Sequencing and analysis of $16 \mathrm{~S}$ rDNA amplification products

After the PCR amplification is completed, the amplified products are sent to Xi'an Kinke Jersey Biotechnology Co., Ltd. for analysis and sequencing, and the $16 \mathrm{~S}$ rDNA sequence fragment of the strain is obtained. The measured sequence was compared and analyzed with 16S rDNA gene sequence on the BLAST program on the NCBI website, and it was determined that the degrading bacterium B5 was Pantoea agglomerans.

(3) Phylogenetic tree

Use analysis software such as MEGA and Clustal $\mathrm{X} 1.38$ to analyze the sequence homology to construct a phylogenetic tree, as shown in the figure 2 .

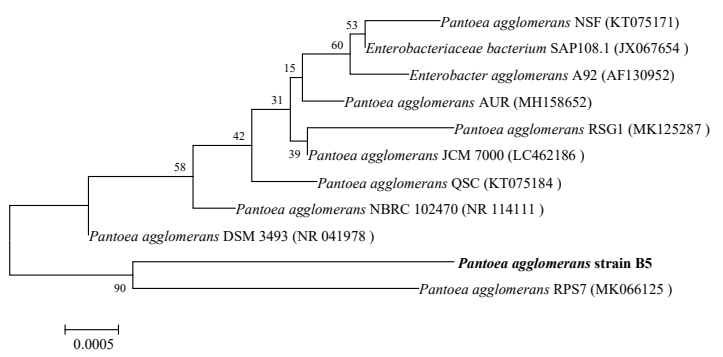

Figure 2. Phylogenetic tree of Pantoea agglomerans strain B5

\subsection{Optimization of phenol degrading bacteria conditions}

(1) Correlation test between cell concentration and phenol degradation ability

The strains were cultured in the acclimation medium to the logarithmic growth phase (OD600 $=0.5-1)$, and the bacteria were collected by centrifugation at 7000rpm for $5 \mathrm{~min}$. Resuspend the bacteria in a re-screened liquid medium containing $500 \mathrm{mg} / \mathrm{L}$ of phenol according to the wet reuse of the bacteria, and the final bacteria content reached $1 \mathrm{~g} / \mathrm{L}, 2 \mathrm{~g} / \mathrm{L}, 4 \mathrm{~g} / \mathrm{L}, 8 \mathrm{~g} / \mathrm{L}, 16 \mathrm{~g} / \mathrm{L}$. Then it was cultured in a constant temperature incubator at $25^{\circ} \mathrm{C}$ and $200 \mathrm{r} / \mathrm{min}$, and samples were taken every 12 hours to monitor the phenol content. Figure 3 shows that the B5 strain with an initial concentration of $8 \mathrm{~g} / \mathrm{L}$ can degrade $500 \mathrm{mg} / \mathrm{L}$ of phenol to $24.8 \mathrm{mg} / \mathrm{L}$ in $36 \mathrm{~h}$.

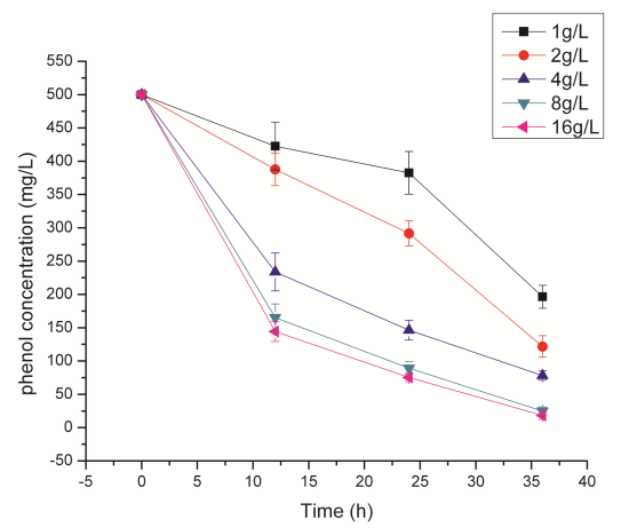

Figure 3. The degradation ability to the phenol

(2) Correlation test of phenol degradation ability of strains under different $\mathrm{pH}$ conditions 
The strains were cultured in the acclimation medium to the logarithmic growth phase (OD600 $=0.5-1)$, and the bacteria were collected by centrifugation at 7000rpm for $5 \mathrm{~min}$. Resuspend the bacteria in re-screened liquid media with different $\mathrm{pH}(\mathrm{pH} 4.5,5.0,5.5,6.0,6.5,7.0)$ to make the content of the bacteria in the medium $8 \mathrm{~g} / \mathrm{L}$. Then it was placed in a constant temperature incubator at $25^{\circ} \mathrm{C}$ and $200 \mathrm{r} / \mathrm{min}$, and samples were taken for 24 hours to monitor the phenol content. Figure 4 shows that the B5 strain has a strong ability to degrade phenol between $\mathrm{pH} 5.5$ and $\mathrm{pH}$ 6.0 .

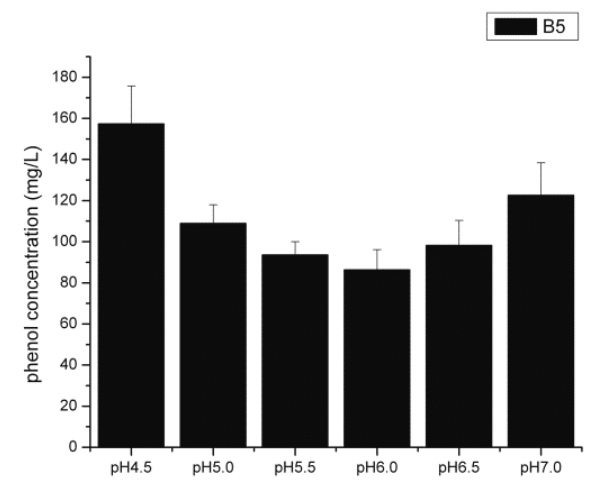

Figure 4. The degradation ability to the phenol in different $\mathrm{pH}$

(3) Correlation test of strain phenol degradation ability under different salt concentration conditions

The strains were cultured in the acclimation medium to the logarithmic growth phase (OD600 $=0.5-1)$, and the bacteria were collected by centrifugation at 7000rpm for $5 \mathrm{~min}$. Resuspend the bacteria with acclimation media containing different sodium chloride concentrations (sodium chloride concentrations are $0.5 \mathrm{~g} / \mathrm{L}, 1 \mathrm{~g} / \mathrm{L}, 2 \mathrm{~g} / \mathrm{L}$, $4 \mathrm{~g} / \mathrm{L}, 8 \mathrm{~g} / \mathrm{L}, 16 \mathrm{~g}, 32 \mathrm{~g} / \mathrm{L}$ ), The cell content in the culture medium was $8 \mathrm{~g} / \mathrm{L}$. Then it was placed in a constant temperature incubator at $25^{\circ} \mathrm{C}$ and $200 \mathrm{r} / \mathrm{min}$, and samples were taken for 24 hours to monitor the phenol content. Figure 5 shows that the B5 strain has a higher ability to degrade phenol in a medium containing $4-8 \mathrm{~g} / \mathrm{L}$ sodium chloride, but has a relatively low ability to degrade phenol in a sodium chloride medium greater than $8 \mathrm{~g} / \mathrm{L}$.

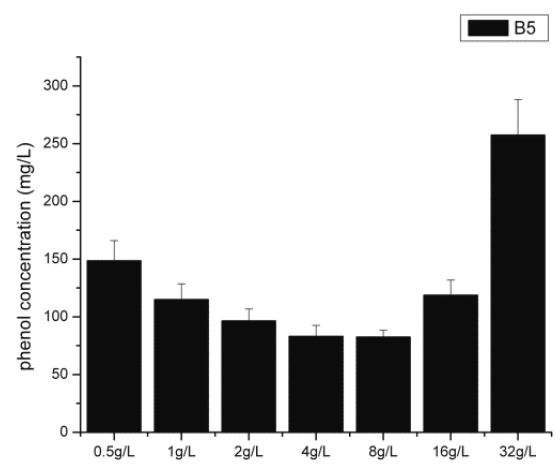

Figure 5. The degradation ability to the phenol with different salt

\section{Conclusion}

In this experiment, we isolated and screened a microbial strain B5 that can use phenol as the sole carbon source and has the ability to efficiently degrade phenol from the soil contaminated by organic matter all year round. Gram staining confirms that it is a Gram-negative cocci, and $16 \mathrm{~S}$ rDNA sequence identification. It is determined that the bacteria is Pantoea agglomerans. Through the subsequent optimization of degradation conditions, it was found that B5 can degrade $500 \mathrm{mg} / \mathrm{L}$ of phenol to $24.8 \mathrm{mg} / \mathrm{L}$ in $36 \mathrm{~h}$, and the ability to degrade phenol between pH5.5-pH6.0 is strong, and the strain contains $4-8 \mathrm{~g} / \mathrm{L}$. Sodium chloride has a higher ability to degrade phenol in the medium. This research can provide certain theoretical guidance for phenol degradation.

\section{Acknowledgments}

The research was funded by the Natural Science Foundation of Gansu Province (20JR5RA207), National Natural Science Foundation of China (NSFC 31860176), Key Research and Development Program of Gansu Province (20YF3FA037), Research projects of Gansu University (2018B-062), Key Research and Development Program of Shanxi Province (2020ZDLSF06-06) and XAWLKYTD012. We are grateful to all anonymous reviewers whose comments improved the quality of the manuscript.

\section{References}

1. MAO Z, YU C, XIN L. Enhancement of phenol biodegradation by Pseudochrobactrum sp. through ultraviolet-induced mutation $[\mathrm{J}]$. Molecular Sciences, 2015, 16: 7320-7333.

2. Wu Zhengyong, Zhao Gaofeng, Zhou Huaidong, etc. The distribution characteristics and potential risks of phenols in the surface water of the Three Gorges Reservoir during the wet season $[\mathrm{J}]$. Environmental Science, 2012, 33(8): 2580-2585.

3. Zhang Zijie. Drainage Engineering (Volume 2). Beijing: China Construction Industry Press, 1996: 115-128.

4. Zhang Fangxi, Jin Chengji. Treatment and Utilization of Phenolic Wastewater. Beijing: Chemical Industry Press, 1983: 48-55.

5. Xiao Zailiang, Lan Shi, Tian Xi, Screening of strong phenol degrading bacteria and the effect of temperature on degradation $[\mathrm{J}]$. Journal of Safety and Environment, 2010, 10(4): 20-22.

6. ZHI Y L, XIAO J G, HUI L, et al. High-throughput screening for a moderately halophilic phenol degrading strain and its salt tolerance response [J]. Molecular Sciences, 2015, 16: 11834-11848.

7. Jian Fangling, Huang Kaina. Preliminary study on the pretreatment of synthetic phenolic resin wastewater. Zhong Yan. Journal of Agricultural Technology College, 2000, 13(1): 40-44.

8. Rodriguez I, Liompart MP, Cela R. Solidphase extraction of phenols. Journal of Chromatography A, 2000, 885(1/2):291-304. 
9. Andrzej W, Trochimczzuk, Michael Streat. Highly polar polymericsorbents characterization and sorptive properties towards phenol andits derivatives. Reactive and Functional Polymers, 2001, 46(3): 259 -271 .

10. Fewson CA. The identity of the gramnegative bacterium NCIB8250. J Gen Microbiol, 1967(48): 107-110. 